\title{
Suitability of somatic cell count, electrical conductivity, and lactate dehydrogenase activity in foremilk before versus after alveolar milk ejection for mastitis detection
}

\author{
M. Khatun, ${ }^{1,2 *}$ R. M. Bruckmaier, ${ }^{3}$ P. C. Thomson, ${ }^{1}$ J. House, ${ }^{1}$ and S. C. García ${ }^{1}$ \\ ${ }^{1}$ School of Life and Environmental Sciences and Sydney Institute of Agriculture, The University of Sydney, Camden 2570, New South Wales, \\ Australia \\ ${ }^{2}$ Bangladesh Agricultural University, Mymensingh 2202, Bangladesh \\ ${ }^{3}$ Veterinary Physiology, University of Bern, 3012, Switzerland
}

\section{ABSTRACT}

Mastitis is responsible for substantial economic loss and significant animal welfare concerns for the dairy industry. Sensors that measure electrical conductivity (EC) and enzyme concentrations of lactate dehydrogenase $(\mathrm{LDH})$ are presently used for automatic detection of mastitis. However, EC is not sensitive enough to detect mastitis, and the ability of LDH activity to identify mastitis caused by different pathogens is a potential option that needs to be investigated. This study was conducted to test the following hypotheses: (a) strict foremilk before milk ejection is more informative in detecting mastitis, in general, than foremilk removed after cows were stimulated for milk ejection; and (b) the value of $\mathrm{LDH}$ activity as a mastitis indicator depends on the type of pathogen associated with the infection. Milk samples (before afternoon milking) from 48 Holstein-Friesian cows at the University of Sydney's dairy farm (Camden, New South Wales, Australia) with $\mathrm{EC}>7.5 \mathrm{mS} / \mathrm{cm}$ in any of the 4 quarters were collected over a period of 2 mo. Quarter milk samples $(\mathrm{n}=343)$ from 48 cows were collected manually in the automatic milking rotary in 3 steps: foremilk before (strict foremilk) and after milk ejection, followed by an aseptic sample for bacteriological culture. The EC $(\mathrm{mS}), \mathrm{LDH}(\mathrm{U} / \mathrm{L}), \mathrm{SCC}$ (cells/mL), and milk protein and fat content (\%) of foremilk in both sampling times were compared and used as predictors for gram-positive and gram-negative mastitis. Quarter $(\mathrm{n}=515)$ observations from 44 cows were analyzed using a logistic mixed or linear mixed model, with cow and quarter nested within cow as random effects. Milk from both sampling times was also assessed by producing a receiver operating characteristic (ROC) curve and calculating the area

Received September 26, 2018.

Accepted May 30, 2019.

*Corresponding author: mkha3293@uni.sydney.edu.au under the curve (AUC) to determine ability to detect mastitis. Overall, EC and LDH were greater and milk protein $(\%)$ was lower in strict foremilk than in milk fractions obtained after milk ejection. Data from strict foremilk samples had slightly higher AUC values (0.98 to 0.99 vs. 0.97 to 0.98 , respectively) than did the afterejection milk samples. Although gram-negative coliform mastitis had significantly higher LDH activity than did gram-positive mastitis (6.19 vs. $5.34 \log _{10} \mathrm{U} / \mathrm{L}$ ), the robustness of this result is questionable due to limited sample size. We concluded that milk samples taken before ejection can influence major mastitis indicators, suggesting that automatic milking system sensors could be modified to monitor milk before ejection for more efficient mastitis detection.

Key words: dairy cow, mastitis, quarter, strict foremilk, milk ejection

\section{INTRODUCTION}

Bovine mastitis is an inflammation of the mammary gland that affects animal welfare and has huge negative economic effects on the dairy industry (Halasa et al., 2007; Huijps et al., 2008). Efficient mastitis detection provides opportunity to implement early and adequate treatment protocols and to avoid excessive use of antibiotics, maintaining good animal health and welfare by reducing soreness, pain and discomfort; enhancing recovery rate; and improving economic return to farmers (Milner et al., 1997; Lehmann et al., 2015). Currently, an increasing number of dairy farmers worldwide are choosing automatic milking systems (AMS), which allow farmers to maximize milking frequency (and potentially milk production per cow) and minimize labor costs (García and Fulkerson, 2005; Hovinen and Pyörälä, 2011; John et al., 2017). In AMS, the sensors that measure electrical conductivity (EC) are the in-line sensors most commonly used to detect mastitis. These sensors can continuously measure concentration of ions in milk 
during the milk harvesting process, albeit with variable results (Kamphuis et al., 2008; Mollenhorst et al., 2012; Khatun et al., 2017). Currently in AMS, EC sensors do not measure strict foremilk present in the gland cistern before oxytocin-induced alveolar ejection from alveoli and smaller milk ducts (Bruckmaier and Blum, 1998; Lehmann et al., 2015). Hence, measurements are based on a mixture of cisternal and alveolar milk (as initial milk is discarded and alveolar milk ejection occurs during the teat cleaning process; Bruckmaier and Hilger, 2001; Bruckmaier et al., 2004b; Dzidic et al., 2004). Previous studies have revealed that the milk composition after alveolar ejection varies from the composition before ejection, with reduced effectiveness for mastitis indicators such as EC and SCC (Bruckmaier et al., 2004b; Bansal et al., 2005; Lehmann et al., 2015). Thus, by discarding and not measuring strict foremilk, AMS may be missing valuable data from potentially the most informative milk with regard to mastitis detection.

On the other hand, the immune mechanisms triggered by major mastitis-causing gram-positive (e.g., Staphylococcaceae, Streptococcaceae) or gram-negative (e.g., Enterobacteriaceae) families are different due to different receptor-induced immunoregulatory activities (e.g., toll-like receptor, LPS, peptidoglycan, lactoferrin; Bradley, 2002; Tietze et al., 2006; Wellnitz et al., 2011). At present, researchers are focusing on immune profile-based in-line monitoring sensors to distinguish specific mastitis pathogens for rapid treatment decision as an alternative to the current time-demanding culture or PCR tests (Nyman et al., 2014). Although enzymes (e.g., lactate dehydrogenase, $\mathbf{L D H}$; at present only commercially available in Herd Navigator, DeLaval) are currently used for automatic detection of mastitis (Chagunda et al., 2006b; Mollenhorst et al., 2012), the ability of LDH activity to identify mastitis originating from different pathogens is uncertain. It appears that the best LDH enzyme-based mastitis marker results were obtained when infections originated from live gram-negative E. coli infection (Sørensen et al., 2015; Hernández-Castellano et al., 2017) or were experimentally induced using dead E. coli cell wall (LPS; Larsen et al., 2010; Lehmann et al., 2013; Wellnitz et al., 2015). Additionally, quarter-level mastitis investigation results in higher sensitivity (Se) and specificity (Sp) than does cow-level investigation (Kamphuis et al., 2008; Mollenhorst et al., 2010). Hence, this study was conducted to test the hypotheses that (a) strict foremilk ejection is more informative in detecting mastitis at the quarter level than is foremilk removed after milk ejection, regardless of causal pathogen; and (b) the value of $\mathrm{LDH}$ activity as an indicator of mastitis depends on the type (e.g., gram-positive, gram-negative) of pathogen associated with the infection.

\section{MATERIALS AND METHODS}

All procedures involving animals were approved by the animal ethics committee of the University of Sydney (project number: 2017/1141). The study was conducted for a period of about 2 mo (Jun. 21 to Aug. 30, 2017).

\section{Experimental Design}

This study included fractionized milk samples to investigate the effectiveness of EC, SCC, LDH activity, milk protein, and fat, individually or in combination, as indicators of mastitis when (a) they were determined from milk collected from individual quarters either before or after ejection, and (b) infection originated from gram-positive versus gram-negative bacteria. Fractional milk samples (before and after ejection) followed by aseptic samples from individual quarters were taken from 48 Holstein-Friesian cows.

\section{Location}

The experiment was conducted at the University of Sydney's Corstorphine pasture-based dairy farm, located in Camden, New South Wales, Australia. The farm had about 85 ha of effective grazing land, mostly with annual ryegrass (Lolium multiflorum) oversown on kikuyu (Pennisetum clandestinum) to feed the cows. A partial mixed ration containing primarily brewer's grain, orange pulp, and pasture silage (lucerne hay, oaten hay) was supplemented when necessary to cover deficits in true pasture. Additionally, all lactating cows (approx. 350) were supplemented with approximately $7 \mathrm{~kg}$ of DM of grain-based commercial pelleted concentrate $(18 \%$ protein) per cow in the postmilking area. A year-round calving system was followed, and an automatic rotary system with 24-unit platform and 5 robotic arms (DeLaval Automatic Milking Rotary, Tumba, Sweden) was used for milking the cows.

\section{Indicators for Mastitis Definition}

Two types of mastitis indicators were used in this study, the first based on bacteriological culture to determine the true infection status of the quarter (Sargeant et al., 2001), and the second based on quarter with mastitis predicted by limiting certain SCC thresholds, as reported by previous studies (Hillerton et al., 1999; Mollenhorst et al., 2010). We used SCC-based indicators to account for (1) decrease of colony-forming units to below detection levels with active inflammation and (2) the possibility of the presence of mastitis pathogens requiring specific culture media (e.g., Mycoplasma spp., Coxiella burnetii) not used in the present study. 
Based on bacteriological culture results, quarters identified with different gram-positive bacteria were defined as gram-positive mastitis, and quarters with coliform bacteria were defined as gram-negative mastitis. Quarters with 2 or more pathogens were classified as mixed mastitis, and quarters with no bacterial growth were classified as negative growth, to be considered as negative control.

In terms of SCC, previous studies classified quarter milk with $>100,000$ cells $/ \mathrm{mL}$ (Hillerton et al., 1999) or $>500,000$ cells $/ \mathrm{mL}$ (Mollenhorst et al., 2010) as mastitis. (The latter authors also considered the presence of abnormal milk.) In the present study, due to the potential influence of milk fractions on SCC level (Sarikaya and Bruckmaier, 2006) and weaker mastitis response with $<300,000$ cells/mL (Hernández-Castellano et al., 2017), we calculated a threshold based on mean plus 1 standard deviation, calculated on a logarithmic scale, of strict foremilk and after-ejection milk samples to define the mastitis quarter with an abnormal SCC range (Gordon et al., 1980). As a result, quarters ( $\mathrm{n}=$ 104) having $>530,000$ cells $/ \mathrm{mL}$ in the strict foremilk and $>440,000$ cells/ $\mathrm{mL}$ in the sample after ejection were considered as quarters with mastitis; the remaining quarters $(\mathrm{n}=411)$ were considered as negative controls. Any quarters identified with clinical mastitis during the sampling process were treated immediately after sampling with an intramammary broad-spectrum antibiotic.

\section{Milk Sample Collection}

Each day, milk samples were collected manually between 1400 and $1700 \mathrm{~h}$ in the automatic milking rotary. Quarter samples were collected from each cow selected based on EC at 3 points: before ejection (strict foremilk); after ejection or after udder stimulation (cleaning the teats); and an aseptic sample for culture.

For the first step of sampling, milk samples were collected immediately after the cow entered the milking parlor, before any milking procedure and without any teat cleaning (i.e., before any tactile stimulation occurred). The first 2 to 3 squirts (foremilk) collected separately from each quarter within approximately 60 $\mathrm{s}$ of touching the udder were considered to be sampled before milk ejection, or strict foremilk. These samples measured approximately $50 \mathrm{~mL}$ each.

In the second step of sampling, after direct tactile stimulation $(\sim 74 \mathrm{~s})$, the udder was further stimulated by rubbing each teat with a towel soaked in warm water containing iodine solution (Iodophor LF12); teats were subsequently dried with tissue paper. After that, milk samples of about $50 \mathrm{~mL}$ each were collected separately from each quarter.
Finally, aseptic samples were collected for bacteriological culture. Thus, for each cow, immediately after the second step of sampling, teats were dipped in iodine solution (Iodophor LF12) and cleaned with a $70 \%$ alcohol-soaked gauze (as modified from Hogan et al., 1999). Immediately after the teat was thoroughly disinfected, milk samples of about $10 \mathrm{~mL}$ were collected from each quarter, following standard procedures to minimize risk of contamination. During milk collection, we followed the same order of quarter sampling, namely, left hind, left front, right hind, and right front, to minimize risks of sampling error.

Immediately after collection, milk samples were transported to the laboratory, where aseptic milk samples were frozen at $-20^{\circ} \mathrm{C}$ until sent to the culture laboratory. Approximately $5 \mathrm{~mL}$ of each sample from strict foremilk and after-ejection milk was separated and frozen at $-80^{\circ} \mathrm{C}$ for $\mathrm{LDH}$ activity analysis. The remaining milk samples were tested for EC and then mixed with Protectol preservative (Thor, Specialties Pty. Ltd., Wetherill Park, Australia) before being sent to a commercial laboratory for SCC (cells per $\mathrm{mL}$ ), milk protein (\%), and milk fat (\%) content analysis.

\section{Criteria for Selection and Post-Admission Exclusion}

Selection Criteria. Forty-eight Holstein-Friesian cows (out of 350 lactating cows) of first to eighth lactation (average $161 \mathrm{DIM}$ ) and having a relatively high EC $\left(\geq 7.5 \mathrm{mS} / \mathrm{cm}\right.$ at milking temperature, $\left.38^{\circ} \mathrm{C}\right)$ in any of the 4 quarters were screened for milk sampling (Norberg et al., 2004). Based on detection of a mean difference in EC of $0.5 \mathrm{mS} / \mathrm{cm}$ between the milk fraction samples [based upon a previous study by Ontsouka et al. (2003)], with a corresponding standard deviation of $0.5 \mathrm{mS} / \mathrm{cm}, 11$ cows would be required, assuming a power of $80 \%$ and threshold significance of $5 \%$, whereas 34 cows would be required to detect a difference of $0.25 \mathrm{mS} / \mathrm{cm}$ (http://statulator.com). The study by Ontsouka et al. (2003) used 16 cows. Our study used 48 cows, with single samples from 31 and repeated samples from 17 cows. Because EC readings vary according to milk temperature, we selected $7.5 \mathrm{mS} / \mathrm{cm}$ arbitrarily to find mastitis quarters with $\mathrm{SCC}$ ranges of at least 425,000 to 531,000 cells $/ \mathrm{mL}$, according to Bruckmaier et al. (2004a). Identified cows were separated from the voluntary milking herd and fed in designated paddocks to allow their milking sessions (twice daily) to be controlled for monitoring and sampling purposes.

Post-Admission Exclusion Criteria. Any cow treated with antibiotic in single or multiple quarters for clinical mastitis was excluded from sampling. One quarter of a cow with adjacent supernumerary teat was not sampled, due to milking inactivity in the AMS. 
Four cows were not included in the analysis due to insufficient amount of sample (time restriction to collect strict foremilk or insufficient milk after ejection).

\section{Laboratory Analysis}

Milk samples collected before and after ejection were analyzed for EC, SCC, LDH activity, and milk protein and fat content.

Electrical Conductivity. Electrical conductivity was measured using a Draminski Model $4 \times 4$ Q MAST mastitis detector (MDQ, Draminski, Olsztyn, Poland) at the University of Sydney M. C. Franklin Laboratory on the day of sample collection. The MDQ is designed to measure electrical resistance (i.e., the inverse of conductivity) in the range of 10 to $1,000 \Omega$. The electrical resistance (ER) value measured by MDQ was converted into EC as follows:

$$
\begin{gathered}
\operatorname{ER}(\Omega)=\text { unit shown in MDQ } / 1.944 \\
\mathrm{EC}(1,000 \mathrm{mS})=\mathrm{EC}(1 \mathrm{~S})=1 \text { reciprocal ohm }(1 / \Omega)
\end{gathered}
$$

Milk samples collected before and after ejection were measured separately, following the same order (right hind, right front, left hind, left front) to match the corresponding vessel of the MDQ, to avoid any intervessel measurement variation. The EC was measured at room temperature $\left(25^{\circ} \mathrm{C}\right)$, and milk was not heated to adjust for milking temperature $\left(38^{\circ} \mathrm{C}\right) \mathrm{EC}$.

Lactate Dehydrogenase Activity. The activity of LDH was measured at the University of Bern, Switzerland, using a commercial test kit LDH International Federation of Clinical Chemistry (Axon Lab AG, Baden, Switzerland) and an automated analyzer (COBAS MIRA, Roche Diagnostics, Basel, Switzerland) with minimum detectable activity of $5 \mathrm{U} / \mathrm{L}$.

SCC, Protein, and Fat. A Bentley 2000 autoanalyzer was used to measure SCC (cells $\times 1,000 / \mathrm{mL}$ ), milk protein (\%), and milk fat (\%), following the manufacturer's protocol (Bentley 2000 Instruments, Chaska, $\mathrm{MN}$ ). The SCC was quantified using the principles of laser-based flow cytometry, whereas milk protein and milk fat were measured by mid-infrared absorption built on a single-beam optical system.

Bacteriological Culture. To identify the specific bacteria responsible for mastitis, sterile milk samples were cultured at the University of Sydney microbiological laboratory. All samples were cultured within $7 \mathrm{~d}$ of collection, using standardized procedures consistent with National Mastitis Council (Hogan et al., 1999) guidelines, with modifications as described by Shum et al. (2009). We assumed that freezing had no influence on the viability of the specific bacteria in this study, although freezing could influence the microbial quality (Murdough et al., 2010; Ruegg et al., 2016). Briefly, gram-positive Streptococcus, Aerococcus, and Enterococcus spp. were identified by their growth in sheep blood agar (SBA), Enterococcal agar, and Rambach agar; and by bile esculin, Christie, Atkins, and Munch-Petersen (CAMP), and leukocyte alkaline phosphatase (LAP) tests. Staphylococcus isolates were identified by growth in SBA, coagulase test, and Gram staining. Gram-negative coliforms were identified by their growth in SBA and MacConkey agar, Gram staining, and potassium hydroxide (slime) test. We did not further differentiate between species of coliform pathogens. Samples that did not yield microbial growth following $48 \mathrm{~h}$ of incubation were classified as negative controls. Isolation of 2 or more bacteria genera from the same sample was considered as nondiagnostic or mixed.

\section{Statistical Analysis}

Data were analyzed using ASReml-R (Butler et al., 2009) built under $\mathrm{R}$ version 3.4.3 (http://www.r -project.org). As the distributions of SCC and $\mathrm{LDH}$ activity were positively skewed, they were $\log$ (base $e$ ) transformed before analysis to stabilize the variance and achieve normality of the outcome variables, or to reduce the leverage of very large values when used as explanatory variables. In total, 515 quarter observations were included in the analysis of sampling times. Other analyses included SCC and LDH activity, from which 3 observations were excluded due to extreme residual deviation $(>3)$ between before- and after-ejection sampling times.

Sampling Time Differences. The differences in the response observations in 2 different sampling times collected before versus after ejection were assessed using the following linear mixed model:

$$
\begin{gathered}
Y=\text { Constant }+ \text { Time }+ \text { Quarter }+ \text { Time } \times \text { Quarter } \\
+ \text { Cow }+ \text { Cow } \cdot \text { Quarter }+\varepsilon,
\end{gathered}
$$

where $Y$ is the response variable [EC, $\ln (\mathrm{SCC})$, $\ln (\mathrm{LDH})$, milk protein, or milk fat], Time = before versus after ejection as fixed effect, Quarter $=$ quarter as fixed effect, Time $\times$ Quarter $=$ interaction between before- versus after-ejection time with quarter, Cow and Cow.Quarter $=$ cow, and quarter nested within cow as random effects, and $\varepsilon=$ random error. Predicted means were calculated with corresponding $95 \%$ confidence intervals. 
Assessment of Sampling Times by Receiver Operating Characteristic Curve. The following logistic generalized linear mixed model (GLMM) was fitted before receiver operating characteristic (ROC) assessment:

$\ln [\pi /(1-\pi)]=\beta_{0}+\beta_{\mathrm{EC}} \mathrm{EC}+\left(\beta_{\mathrm{LDH}}+\gamma_{\mathrm{LDH} . \mathrm{Time}}\right) \ln (\mathrm{LDH})$ $+\beta_{\mathrm{MP}} \mathrm{MP}+\beta_{\mathrm{MF}} \mathrm{MF}+$ Time $+u_{C}+u_{C Q}$,

where $\pi=P(Y=1)$ is the probability that a particular quarter has mastitis at the specified SCC threshold at a particular test session; EC, $\ln (\mathrm{LDH}), \mathrm{MP}$ (milk protein), MF (milk fat), and Time (sampling times), are predictors with interaction of $\ln (\mathrm{LDH})$ with sampling times (specified as $\gamma_{\text {LDH.Time }}$ ), as a fixed effect. Note that $\beta_{\mathrm{EC}}, \beta_{\mathrm{LDH}}, \beta_{\mathrm{MP}}$, and $\beta_{\mathrm{MF}}$ specify the overall linear effects of the 4 variates, and $u_{C}$ and $u_{C Q}$ are the random Cow and Cow.Quarter effects.

Construction of ROC curves was performed using the pROC package in $\mathrm{R}$ (version 3.4.4; Robin et al., 2011). The ROC assessment graphically illustrates the diagnostic test to present sensitivity (Se) versus the complement of specificity $(1-\mathrm{Sp})$ for varying cut points (Hanley and McNeil, 1982; Khatun et al., 2018). The cut points are determined for different probabilities (or linear predictors) of the fitted GLMM. The generated area under the curve (AUC) value from the ROC curve is used to measure diagnostic test performance, classified as excellent (0.9 to 1$)$, good (0.8 to 0.9 ), fair (0.7 to 0.8$)$, poor (0.6 to 0.7$)$, or fail (0.5 to 0.6; Swets, 1988). These ROC curves and accompanying AUC values are evaluated at both sampling times (before and after ejection). Test performance is also evaluated using Youden's index $(J=\mathrm{Se}+\mathrm{Sp}-1)$, selecting a cutoff point at which the index is maximized (Ruopp et al., 2008).

Effect of Sampling Times on EC Measurement. To estimate the effect of sampling time (before or after ejection) on EC, we initially constructed a multivariable logistic GLMM with 4 predictor variables (EC, LDH activity, milk protein, and milk fat), including interaction effects with sampling times. Following a manual backward elimination procedure to drop nonsignificant variables, the final model used for EC association was as follows:

$$
\begin{aligned}
& \ln [\pi /(1-\pi)]=\beta_{0}+\left(\beta_{\mathrm{EC}}+\gamma_{\mathrm{EC} . \mathrm{Time}}\right) \mathrm{EC} \\
& +\left(\beta_{\mathrm{LDH}}+\gamma_{\mathrm{LDH} . \text { Time }}\right) \ln (\mathrm{LDH})+\text { Time }+u_{C}+u_{C Q}
\end{aligned}
$$

where $\pi=P(Y=1)$ is the probability that the particular quarter had mastitis with $>530,000$ cells $/ \mathrm{mL}$ in the sample before ejection and $>440,000$ cells $/ \mathrm{mL}$ after ejection (as described in "Indicators for Mastitis Definition") at a particular test session; EC and $\ln (\mathrm{LDH})$ were predictors having interaction with sampling times (Time), as fixed effects; and $u_{C}$ and $u_{C Q}$ were random Cow and Cow.Quarter effects. Note that $\beta_{\mathrm{EC}}$ and $\beta_{\mathrm{LDH}}$ specify the overall linear effect of these 2 variates, and $\gamma_{\text {EC.Time }}$ and $\gamma_{\text {LDH.Time }}$ are used to specify interactions for example, a deviation of the linear trend for the particular sampling times, before versus after ejection.

Difference Between Gram-Positive and GramNegative Mastitis. The differences in the response observations in gram-positive and gram-negative mastitis were assessed using the following linear mixed model:

$Y=\beta_{0}+$ Culture $+\left(\beta_{\text {DIM }}+\gamma_{\text {Culture.DIM }}\right)$ DIM $+u_{C}+u_{C Q}$,

where $Y$ is the response variable (EC, $\ln (\mathrm{SCC})$, $\ln (\mathrm{LDH})$, milk protein, or milk fat); Culture = grampositive versus gram-negative mastitis as fixed effect; $\mathrm{DIM}=$ days in milk as fixed effect; $\beta_{\text {DIM }}$ specifies the overall linear effect of DIM, and $\gamma_{\text {Culture.DIM }}$ is used to specify the Culture $\times$ DIM interaction. Predicted means were calculated with corresponding $95 \%$ confidence intervals.

Comparison of SCC and LDH Activity to Predict Mastitis. To compare the effectiveness of SCC and $\mathrm{LDH}$ activity to predict gram-positive or gramnegative mastitis, each of these variables was standardized or rescaled, for example, $x^{\prime}=(x-\bar{x}) / S D_{x}$, to compare variables across different scales, using the scale function in $\mathrm{R}$ version 3.2.5 (http://www.r-project .org). The rescaled SCC or LDH activity data were assessed individually because of collinear association between them $\left(r_{s} \geq 0.8\right)$, using the following nonlinear model (spline function in $\mathrm{R}$ ):

$$
\ln [\pi /(1-\pi)]=\beta_{0}+\beta_{1} x^{\prime}+s\left(x^{\prime}\right)+u_{C}+u_{C Q},
$$

where $x^{\prime}$ is either the rescaled SCC or the rescaled LDH. Each is included as a fixed linear effect, together with a nonlinear spline term, $s\left(x^{\prime}\right)$, specified as a random effect in the model, and also included $u_{C}$ and $u_{C Q}$ as random Cow and Cow.Quarter effects. Rescaling allowed for displaying both predictors with the corresponding fitted values on the same plot.

Correlation Test. To assess for correlation between predictors, pairwise Spearman's correlations were obtained between the 3 variables, namely $\mathrm{EC}, \ln (\mathrm{SCC})$, and $\ln (\mathrm{LDH})$, independent of mastitis pathogen. Because of large variabilities in milk fat (particularly) and 
Table 1. Model-based means (95\% CI in parentheses) of electrical conductivity, lactate dehydrogenase activity, SCC, and milk protein and milk fat concentrations in milk samples before and after ejection, from linear mixed models $^{1}$

\begin{tabular}{lccc}
\hline & \multicolumn{2}{c}{ Times $^{3}$} \\
\cline { 2 - 3 } Responses $^{2}$ & Before ejection & After ejection & \multirow{2}{*}{$P$-value } \\
\hline EC $(\mathrm{mS})$ & 5.08 & 4.60 & $<0.001^{* * *}$ \\
SCC $(\times 1,000$ cells $/ \mathrm{mL})$ & $(4.97,5.19)$ & $432.41,4.69)$ & 0.18 \\
& $(435.79$ & $(350.69,533.26)$ & \\
LDH $(\mathrm{U} / \mathrm{L})$ & $200.79,678.99)$ & 160.36 & $0.036^{*}$ \\
Milk protein $(\%)$ & $(171.56,234.91)$ & $(139.55,184.28)$ & $0.001^{* *}$ \\
Milk fat $(\%)$ & 3.41 & $(3.59,3.67)$ & 0.86 \\
& $(3.33,3.49)$ & 2.86 & $0.66,3.05)$ \\
\hline
\end{tabular}

${ }^{1}$ Linear mixed models included 4 variables (electrical conductivity, lactate dehydrogenase activity, protein content, and fat content in milk), with random effect estimates for each cow and cow-quarter. $\mathrm{n}=515$ quarters.

${ }^{2} \mathrm{EC}=$ electrical conductivity; $\mathrm{LDH}=$ lactate dehydrogenase activity.

${ }^{3}$ Before ejection $=$ comparison only before alveolar milk ejection; after ejection $=$ comparison only after alveolar milk ejection.

${ }^{*} P<0.05 ;{ }^{* *} P<0.01 ;{ }^{* * *} P<0.001$.

protein content between milkings, we did not calculate the correlation of milk fat and protein with these 3 variables.

\section{RESULTS}

One cow had only 3 functional quarters, and several cows were sampled on several days as a result of the ECthreshold criterion ( 7 cows $\times 2$ times, 5 cows $\times 3$ times, 4 cows $\times 5$ times, and 1 cow $\times 6$ times). This resulted in 686 samples from 48 cows for the laboratory analysis and 343 samples for culture test. On average, milk samples before ejection were collected within $60 \mathrm{~s}$ of udder touch (Bruckmaier et al., 2004b). This limited the volume of milk collected, and therefore some measurements were missing in the analysis (insufficient volumes were 27 samples for SCC and 115 samples for fat and protein). Likewise, for milk sampled after ejection, we also found cases of insufficient volume (18 samples for SCC and 48 samples for protein and fat measurements) due to hostile behavior mostly by primiparous cows or attributable to pain from clinical mastitis, or due to machine measurement error with limited samples. Additionally, after laboratory measurement of SCC and LDH activity, 3 quarters showed extreme deviation for SCC and LDH values between 2 sampling times and therefore were excluded from the analysis.

\section{Bacteria Identification and Difference Between Sampling Times}

Out of 343 tested quarters of 48 cows, 157 (45.8\%) were gram-positive, $6(1.8 \%)$ were gram-negative (co- liform), 6 (1.8\%) were mixed, and 174 (50.7\%) did not have bacterial growth (negative control). Out of the 157 gram-positive pathogens, Corynebacterium spp. (44\%, quarter samples $=69)$, Streptococcus uberis $(17.2 \%$, quarter samples $=27$ ) and Streptococcus dysgalactiae $(13.4 \%$, quarter samples $=21)$, accounting for approximately $70 \%$ of all infections. Other mastitis-causing gram-positive pathogens were CNS $(9.6 \%$, quarter samples $=15)$, Streptococcus agalactiae $(5.7 \%$, quarter samples $=9)$, coagulase-positive Staphylococcus $(3.2 \%$, $\mathrm{n}=5)$, Bacillus spp. $(2.6 \%, \mathrm{n}=4)$, Enterococcus faecalis $(1.9 \%, \mathrm{n}=3)$, Trueperella pyogenes $(1.3 \%, \mathrm{n}=$ $2)$, Aerococcus spp. $(0.6 \%, \mathrm{n}=1)$, and environmental Streptococcus spp. $(0.6 \%, \mathrm{n}=1)$. Milk before ejection had significantly greater EC $(P<0.001)$ and LDH activity $(P=0.036)$ but lower milk protein $(P<0.001)$ than after-ejection samples (Table 1).

\section{Assessment of Sampling Times by ROC}

In the ROC evaluation (Table 2), we obtained excellent $(\mathrm{AUC}>0.9)$ mastitis prediction ability for both before- and after-ejection samples at different SCC thresholds. Samples before ejection had numerically higher or equal mastitis prediction ability compared with after ejection, as specified by the AUC values $(0.98$ to 0.99 vs. 0.97 to 0.98 , respectively; $P>0.1$ ). At the optimum cutoff (maximum value of Youden's index) the differences between Se and Sp between before- versus after-ejection times were $(-0.34 \%$ to $0.8 \%$, and $-0.9 \%$ to $8.4 \%$, respectively), with an average $3.6 \%$ higher Sp among before-ejection samples. 


\section{Effect of Sampling Times on EC Measurement}

In assessment with backward elimination of the multivariable model including EC, LDH activity, milk protein, and milk fat, only EC and LDH activity had significant interactions with sampling time. Hence the final model, including $\mathrm{EC}$ and $\mathrm{LDH}$, shows that the EC in milk collected before milk ejection had greater power to predict mastitis than did milk collected after ejection. Among EC levels up to $5 \mathrm{mS}$, there was no substantial difference in the probability of mastitis between sampling times. However, above $5 \mathrm{mS}$, the difference in the probability of mastitis increased much more rapidly with increasing $\mathrm{EC}$ in the samples taken before milk ejection than it did in those obtained after milk ejection (Figure 1 ).

\section{Differences Between Gram-Positive and Gram-Negative Mastitis}

The differences between gram-positive and gram-negative mastitis for EC, SCC, LDH activity, milk protein, and milk fat, with or without separating the sampling times, are presented in Table 3. Irrespective of sampling time, and despite the relatively small sampling size for mastitis associated with gram-negative pathogens, gram-negative coliform mastitic milk had significantly greater LDH activity $(P<0.01)$ and higher protein levels $(P<0.05)$, and showed a trend $(P=0.09)$ for higher SCC, than did gram-positive mastitic milk. We discovered a significant effect of DIM on protein content
$(P<0.05)$ as well as interaction of DIM with pathogen type $(P<0.01)$. Analysis also revealed a significant $(P<0.01)$ interaction of $\mathrm{LDH}$ activity with pathogen type.

After separating the sampling times, gram-negative mastitis showed significantly greater EC $(P<0.01)$ and LDH activity $(P<0.05)$ than did the gram-positive mastitis in the samples taken before milk ejection. In the case of after-ejection sampling time, gram-negative mastitic milk had significantly $(P<0.01)$ greater LDH activity than gram-positive mastitic milk did. In addition, gram-positive mastitic milk had a significantly lower protein content compared with gram-negative $(P$ $=0.008$ ) mastic milk, although we found a significant interaction of DIM with pathogen type $(P<0.001)$.

\section{Comparison of SCC and LDH Activity to Predict Mastitis}

After re-scaling (standardizing), both SCC and LDH activity showed positive associations with the probability of gram-positive mastitis (Figure 2) and gram-negative mastitis (Figure 3 ). In the case of grampositive mastitis, SCC $(P=0.009)$ and LDH activity $(P=0.012)$ had similar predicted probabilities of mastitis. However, LDH activity, expressed as standardized $\ln (\mathrm{LDH})$, showed a stronger positive association with gram-negative coliform mastitis $(P=0.027)$ than did standardized $\ln (\mathrm{SCC})(P=0.044)$, indicating better predictive ability of $\mathrm{LDH}$.

Table 2. Analysis of receiver operating characteristic (ROC) curves, sensitivity, and specificity at optimum cutoff value for prediction of mastitis with different thresholds of SCC (gold standard for definition of mastitis) by multivariable generalized linear mixed model ${ }^{1}$

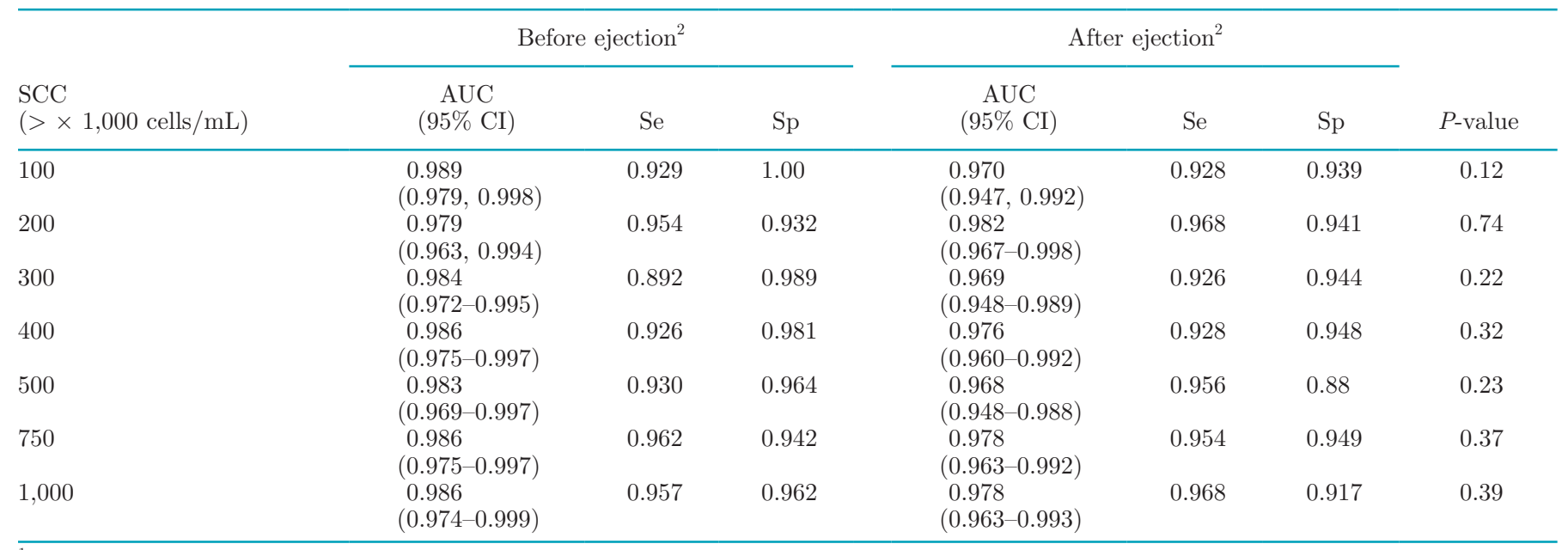

${ }^{1}$ Logistic generalized linear mixed models included 4 variables (electrical conductivity, lactate dehydrogenase activity, protein content, and fat content in milk), with random effect estimates for each cow and cow-quarter. $\mathrm{n}=512$ quarters; gram-positive mastitis $=232$; gram-negative mastitis $=6$; mixed mastitis $=5$; negative control $=269$.

${ }^{2}$ Before ejection = comparison only before alveolar milk ejection; after ejection = comparison only after alveolar milk ejection; AUC $=$ area under the curve; Se = sensitivity at Youden's index (cutoff point where index is maximized); Sp = specificity at Youden's index. 
Table 3. Difference between gram-positive and gram-negative (coliform) mastitis for electrical conductivity, SCC, lactate dehydrogenase (LHD) activity, milk protein content, and milk fat content by linear mixed models ${ }^{1}$

\begin{tabular}{|c|c|c|c|}
\hline Item $^{2}$ & Gram-positive $^{3}$ & Gram-negative $^{3}$ & $P$-value \\
\hline \multicolumn{4}{|c|}{ Electrical conductivity $(\mathrm{mS})$} \\
\hline Both times & $4.88(4.71,5.04)$ & $5.18(4.48,5.88)$ & 0.23 \\
\hline Before ejection & $5.24(5.02,5.46)$ & $6.63(5.70,7.56)$ & $0.003^{* *}$ \\
\hline After ejection & $4.64(4.45,4.84)$ & $4.73(3.97,5.50)$ & 0.66 \\
\hline \multicolumn{4}{|c|}{ SCC $\left(\log _{10}\right.$ cells $\left./ \mathrm{mL}\right)$} \\
\hline Both times & $6.44(6.06,6.83)$ & $7.03(6.13,7.92)$ & 0.09 \\
\hline Before ejection & $6.67(6.23,7.12)$ & $7.55(5.77,9.33)$ & 0.14 \\
\hline After ejection & $6.29(5.90,6.68)$ & $7.01(5.86,8.16)$ & 0.17 \\
\hline \multicolumn{4}{|c|}{ Lactate dehydrogenase $\left(\log _{10} \mathrm{U} / \mathrm{L}\right)$} \\
\hline Both times & $5.34(5.09,5.58)$ & $6.19(5.47,6.91)$ & $0.003^{* *}$ \\
\hline Before ejection & $5.52(5.16,5.88)$ & $6.55(4.95,8.16)$ & $0.04^{*}$ \\
\hline After ejection & $5.23(4.99,5.47)$ & $6.33(5.46,7.19)$ & 0.008 \\
\hline \multicolumn{4}{|l|}{ Protein \% } \\
\hline Both times & $3.68(3.45,3.91)$ & $3.93(3.54,4.32)$ & $0.02 *$ \\
\hline Before ejection & $3.64(3.34,3.94)$ & $3.67(3.08,4.27)$ & 0.12 \\
\hline After ejection & $3.75(3.54,3.95)$ & $4.15(3.75,4.54)$ & $0.008^{* *}$ \\
\hline \multicolumn{4}{|l|}{ Fat $\%$} \\
\hline Both times & $2.84(2.42,3.26)$ & $2.55(1.58,3.53)$ & 0.35 \\
\hline Before ejection & $2.70(2.14,3.25)$ & $2.53(0.63,4.43)$ & 0.71 \\
\hline After ejection & $2.85(2.46,3.24)$ & $2.47(1.52,3.42)$ & 0.30 \\
\hline
\end{tabular}

${ }^{1}$ Linear mixed models with random effects for cow and cow-quarter. $\mathrm{n}=238$ quarters.

${ }^{2}$ Both times = comparison without separating sampling times; before ejection = comparison only before alveolar milk ejection; after-ejection = comparison only after alveolar milk ejection.

${ }^{3}$ Gram-positive $\mathrm{n}=232$; gram-negative $\mathrm{n}=6$. Means shown, with $95 \%$ CI in parentheses.

$* P<0.05 ;{ }^{* *} P<0.01$.

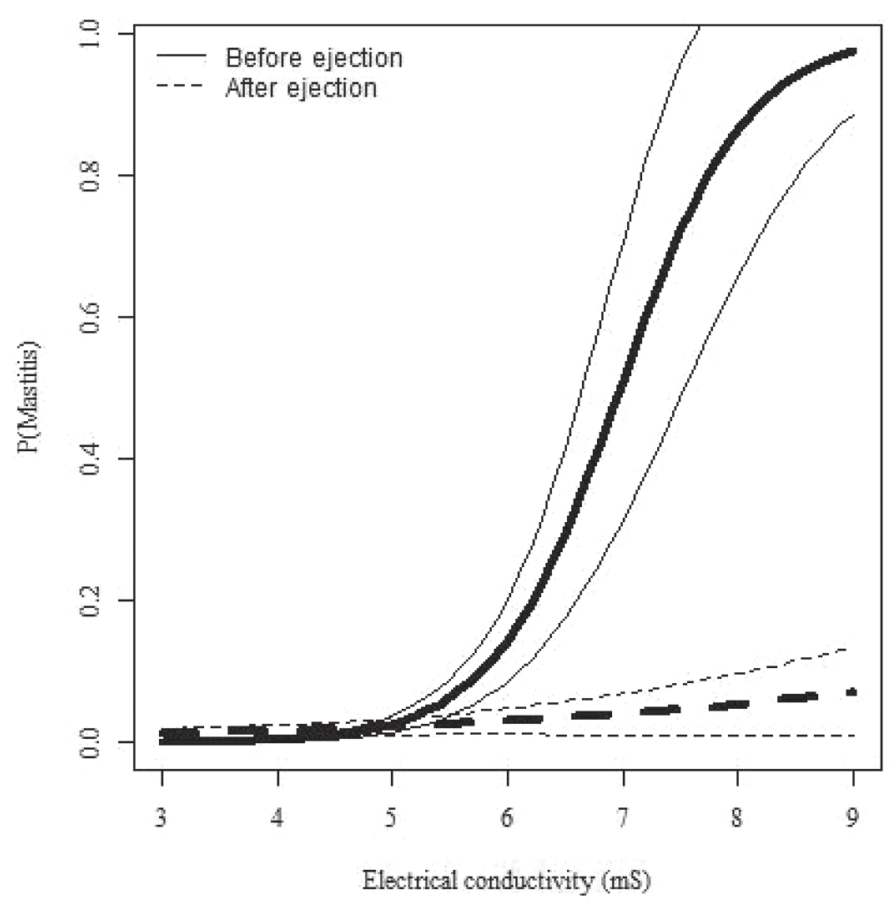

Figure 1. Effects of sampling times before milk ejection (solid lines) and after milk ejection (dashed lines) on electrical conductivity $(\mathrm{mS}$, mean $\pm \mathrm{SE})$ to predict mastitis; $\mathrm{n}=515$ quarters. Quarters having $>530,000$ cells $/ \mathrm{mL}$ in milk before ejection and $>440,000$ cells $/ \mathrm{mL}$ after ejection were considered mastitic $(\mathrm{n}=104)$, and other quarters were negative control $(\mathrm{n}=411)$. This logistic model included electrical conductivity, lactate dehydrogenase activity, and sampling times as fixed effects, and cow or quarter nested within cow as random effects.

\section{Correlations}

Overall, we observed a strong positive correlation between SCC and LDH activity $\left(r_{\mathrm{s}}=0.89\right)$. The correlations of EC with LDH activity and SCC were similar $\left(r_{\mathrm{s}}\right.$ for both $\left.=0.61\right)$. All the $r_{\mathrm{s}}$ values were Spearman correlation coefficients, without accounting for quarter, nested within cow, thus representing crude associations between pairs of parameters.

\section{Pathogen-Specific Variation in SCC and LDH Responses}

We found variations in average SCC $(2,119.37$, $5,387.83,2,318.40,1,434.50) \times 1,000$ cells $/ \mathrm{mL}$ and average LDH activity $(215.42,1619.87,351.56,140.13$ $\mathrm{U} / \mathrm{L}$ ) responses between gram-positive, gram-negative, mixed mastitis, and control groups, respectively. Grampositive Aerococcus spp., coagulase-positive Staphylococcus, E. faecalis, Strep. dysgalactiae, Strep. uberis, and Trueperella pyogenes had SCC responses and LDH activity similar to those of gram-negative coliforms (Figure 4).

\section{DISCUSSION}

The main objective of this study was to compare milk sampled before and after ejection in their potential abilities as mastitis predictors. Our study has revealed 
that milk sampled before ejection is more informative for monitoring mastitis-related changes and therefore has higher mastitis prediction ability. Previous studies of healthy cows have reported that milk samples taken after ejection reduce the effectiveness of potential mastitis indicators such as SCC levels and LDH activity (Sarikaya and Bruckmaier, 2006; Lehmann et al., 2015). Such comparisons among cows with mastitis in this study support previous findings that sampled milk fractions influence potential mastitis indicators with significance (e.g., EC, LDH activity) or without significance (e.g., SCC) but also milk composition such as milk protein (Sarikaya and Bruckmaier, 2006).

Significantly higher EC in the before-ejection sample than after ejection might be associated with regulation of the milk osmotic pressure by higher ion concentrations (e.g., $\mathrm{Na}, \mathrm{Cl}$ ), which could be exacerbated by mastitis-related damage to the tight junctions (Nguyen and Neville, 1998; Ontsouka et al., 2003). Severe damage to tight junctions might lead to a higher EC, with passing of somatic cells at abnormal milk ranges, with greater prediction probability of before-ejection samples with $>530,000$ cells $/ \mathrm{mL}$ than after-ejection samples with $>440,000$ cells $/ \mathrm{mL}$ (Gordon et al., 1980). However, an

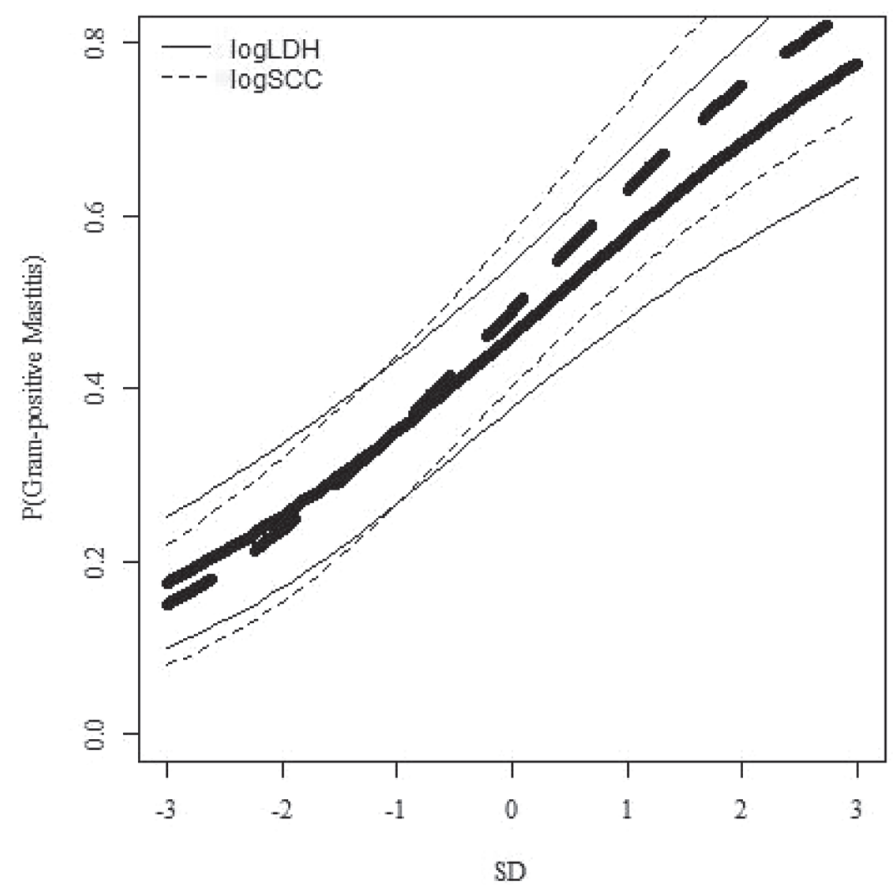

Figure 2. Prediction of gram-positive mastitis by SCC (dashed lines, estimated value $\pm \mathrm{SE}$ ) and by lactate dehydrogenase activity (LDH; solid lines, estimated value $\pm \mathrm{SE}) ; \mathrm{n}=275$ quarters. This logistic model included rescaled SCC or LDH (expressed as number of SD from the mean) as fixed effects, with cow or quarter nested within cow as random effects. Because of positively skewed distribution, SCC and LDH data were log-transformed.

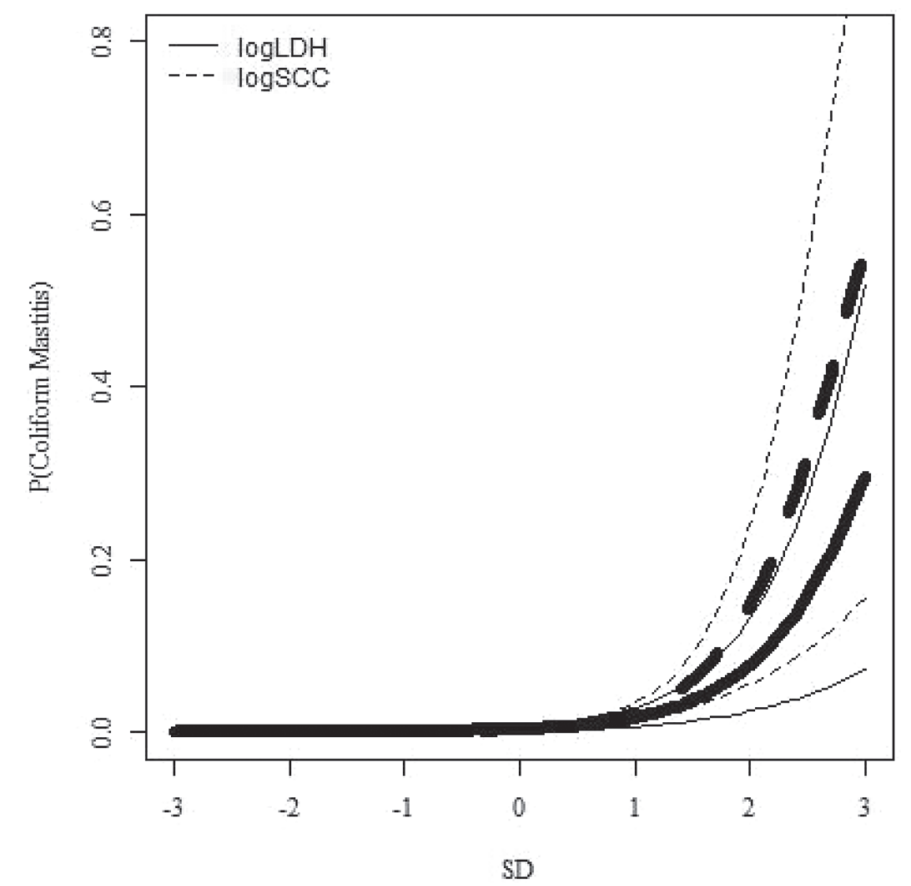

Figure 3. Prediction of gram-negative mastitis by SCC (dashed lines, estimated value $\pm \mathrm{SE}$ ) and lactate dehydrogenase activity (LDH; solid lines, estimated value $\pm \mathrm{SE}$ ); $\mathrm{n}=506$ quarters. This logistic model included rescaled SCC or LDH (expressed as number of SD away from the mean) as fixed effects, with cow or quarter nested within cow as random effects. Because of positively skewed distribution, SCC and LDH data were log-transformed.

SCC threshold much higher than 100,000 to 200,000 cells $/ \mathrm{mL}$ would result in potential false-negative subclinical mastitis detection (dos Reis et al., 2011). It is worth noting that the predictors in our model (e.g., EC, LDH) might be affected by time elapsed from the start of infection and also by the degree of infection (Højsgaard and Friggens, 2010). Hence, an experimental longitudinal study, with in-depth observation of strict foremilk at different ranges of SCC, could assist in better prediction of subclinical mastitis. Overall, this is important because, currently, higher EC, as an indicator for mastitis detection in AMS, is based on milk samples taken after ejection; milk ejection occurs during teat cleaning, meaning that the most informative data are lost (Kamphuis et al., 2008; Khatun et al., 2017). Thus the current system results in insufficient accuracy in the EC sensor to identify subclinical or clinical mastitis in cows (Hamann and Zecconi, 1998). The situation could potentially be improved by using milk taken before ejection (Bruckmaier et al., 2004b).

The nonsignificant differences in SCC $(P=0.18)$ in milk sampled before ejection compared with milk taken after ejection accords with the results reported in a previous study in healthy quarters (Ontsouka et al., 
2003). In our study, the reason behind such nonsignificance might be related to our smaller sample size, with $<50 \%$ mastitic quarters, or to the delayed effect of mild ejection, as it took $60 \mathrm{~s}$ to collect before-ejection samples (within the recommended lag time of 50 to 100 s) instead of $40 \mathrm{~s}$ (recommended time required for strict foremilk before ejection) due to different management situations (Bruckmaier and Hilger, 2001; Bruckmaier et al., 2004b). Additionally, 8 quarters were dipped before the sampling procedure, leading to missing data for before-ejection milk samples for the comparison.

The lower protein content in the milk of beforeejection samples might be due to mastitis-related damage to the tight junctions, with regulation of the milk osmotic pressure by higher levels of electrolytes than after-ejection samples (Nguyen and Neville, 1998; Ontsouka et al., 2003). Moreover, numerically lower $(P=$ 0.86 ) fat content in milk before ejection might be due to lower specific gravity, as reported previously (Ontsouka et al., 2003).
We further evaluated our hypothesis using ROC assessment, which is a useful tool for assessing performance in predicting clinical mastitis (Khatun et al., 2018). In the ROC analysis, the mastitis diagnostic test in this study may be considered excellent (AUC > 0.9) compared with those used in other studies (AUC $\leq$ 0.73; Norberg et al., 2004; Mollenhorst et al., 2010; Petzer et al., 2017). This might be due to our prediction model including LDH activity, milk protein, and milk fat in addition to EC, with the additional parameter increasing the AUC values. Moreover, the temperature differences in EC measurement in our study (e.g., room temperature) as opposed to those used in other studies (e.g., milking temperature, $38^{\circ} \mathrm{C}$ ) might also responsible for such differences. However, the current approach of using multiple measurements produced results similar to those of a previous study that used single measurements, comparing the benefits of before-ejection samples versus after-ejection samples (Bruckmaier et al., 2004b). Hence, despite statistical nonsignificance,

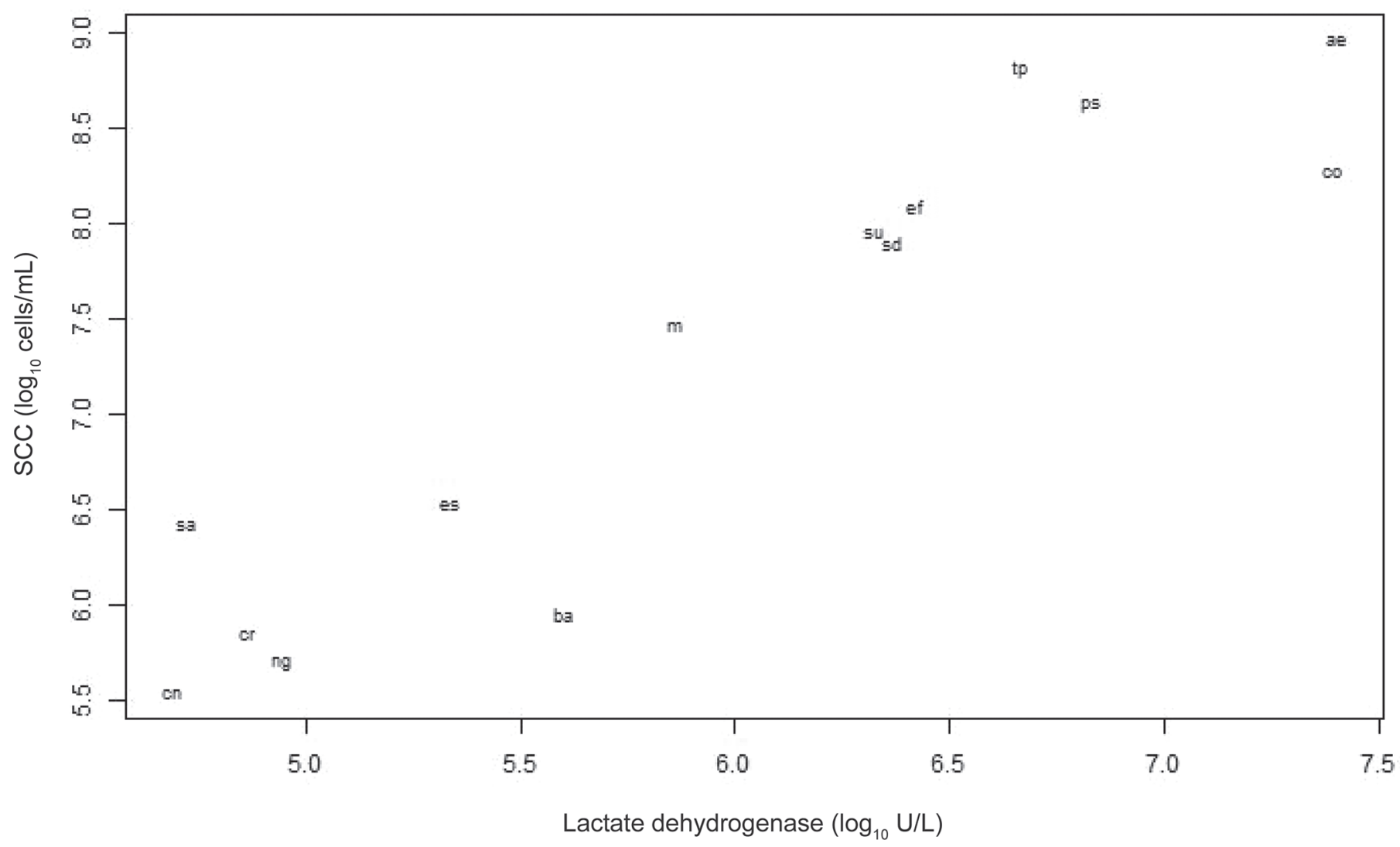

Figure 4. Concentrations of SCC $\left(\log _{10}\right.$, cells per $\left.\mathrm{mL}\right)$ and lactate dehydrogenase concentrations $\left(\mathrm{LDH} ; \log _{10}, \mathrm{U} / \mathrm{L}\right)$ in mastitis caused by different gram-positive and gram-negative bacteria $(\mathrm{n}=512$ quarters $)$. Measured bacteria are as follows: ae $=$ Aerococcus spp.; ba $=$ Bacillus spp.; $\mathrm{cn}=$ coagulase-negative Staphylococcus; $\mathrm{co}=$ coliform bacteria; $\mathrm{cr}=$ Corynebacterium $\mathrm{spp} . ;$ ef $=$ Enterococcus faecalis; es $=$ environmental Streptococcus; $\mathrm{m}=$ mixed species; $\mathrm{ng}=$ no growth; $\mathrm{ps}=$ coagulase-positive Staphylococcus; $\mathrm{sa}=$ Streptococcus agalactiae $;$ sd $=$ Streptococcus dysgalactiae; $\mathrm{su}=$ Streptococcus uberis; $\mathrm{tp}=$ Trueperella pyogenes. 
the numerically higher AUC values in our study at different SCC thresholds, with, on average, 3.6\% higher Sp of before-ejection samples, show that about 4 more mastitic cows (out of 100) will be correctly classified this way than by looking at after-ejection samples.

Significantly higher EC only in before-ejection samples (not in after-ejection samples or in the combined results of samples taken at both times) in cases of gramnegative mastitis compared with gram-positive mastitis further support the better efficiency of before-ejection samples for mastitis detection. As in previous studies, we found similar patterns of higher SCC response and LDH activity by gram-negative coliform mastitis, likely associated with greater destruction of tight junctions with cell disruption (Wellnitz et al., 2011, 2016; Hernández-Castellano et al., 2017). Differential LDHbased adaptive immune activation but similar SCCbased innate immune activation systems might explain the differences in the $\mathrm{LDH}$ activity $(P=0.003)$ and SCC $(P=0.09)$ responses between gram-positive and gram-negative mastitis, respectively (Hiss et al., 2007; Hernández-Castellano et al., 2017). Higher protein content in gram-negative mastitis $(3.93 \%$ vs. $3.68 \%, P=$ 0.02 ) might be due to effects of lower DIM (158 vs. 186 d) than among gram-positive mastitis groups (Auldist et al., 2007). Overall, in this pathogen-specific analysis, the robustness of the outcomes warrants further investigation due to limited sample size (only 6), and should be investigated in larger numbers of samples from different parities with diversified pathogens.

Separate comparison after re-scaling (because of different data scales) of SCC and LDH activity data was intended to better evaluate the relevance of types of mastitis (gram-positive vs. gram-negative) for rapid inline detection in AMS. Similar gram-positive mastitis prediction probability of SCC and $\mathrm{LDH}$ activity but distinct gram-negative mastitis prediction probability of $\mathrm{LDH}$ activity indicates that $\mathrm{SCC}$ is a valid marker from which to obtain alerts against gram-positive mastitis, whereas LDH activity is particularly useful in detection of gram-negative mastitis (Chagunda et al., 2006a; Sørensen et al., 2015; Hernández-Castellano et al., 2017). However, gram-negative mastitis prediction probability needs to be further evaluated using a larger sample size.

We also noticed remarkable differences in SCC response and LDH activity by different gram-positive bacteria, compared with those observed in gram-negative coliforms. This is in agreement with using a combined SCC-LDH response to differentiate gram-positive and gram-negative mastitis (Hernández-Castellano et al., 2017). Another potential advantage of such an approach, using combined SCC and LDH, would be to detect chronic, latent mastitis status where there is scar tissue formation, with blockage of the bloodmilk barrier that would prevent a massive SCC influx (Nickerson, 1993; Hébert et al., 2000). Further improvement of combined SCC-LDH analysis would be possible by incorporating other potential markers such as milk albumin or other protein to improve the mastitis pathogen differentiation capacity of the in-line sensors. This will be the focus for future studies with larger numbers of samples of different pathogens.

In this study, the predominant mastitis-causing pathogens $(\sim 44 \%)$ were Corynebacterium spp., and these might be associated with poor milking hygiene practice (lack of teat disinfection) in AMS before milking (Haltia et al., 2006). However, Corynebacterium spp. are considered minor subclinical mastitis pathogens, representing contamination of milk with bacteria present in the teat canal, rather than real presence of an intramammary infection (Gonçalves et al., 2016).

\section{CONCLUSIONS}

We evaluated the sensitivity of strict foremilk (samples taken before milk ejection) and foremilk samples taken after milk ejection for quarter-level mastitis prediction. In summary, SCC, LDH activity, and milk protein levels were strongly associated with mastitis. Foremilk sampled before milk ejection was more sensitive for detection of mastitis than foremilk harvested after milk ejection, which is induced by udder preparation, including teat cleaning in AMS systems. Both LDH activity and milk protein contents were higher in quarters with gram-negative coliform mastitis than in quarters with mastitis caused by gram-positive bacteria. Overall, our results suggest that, in the future, sensors could be modified to monitor milk removed before teat cleaning, to improve the ability of AMS to detect mastitis.

\section{ACKNOWLEDGMENTS}

The authors thank Sherry Catt and Ann-Marie House (laboratory staff of the University of Sydney, Australia), Michelle Heward (administrative staff of the University of Sydney), and Mardhati Mohammad (PhD student at the University of Sydney), and Yolande Zbinden (laboratory staff of the University of Bern, Switzerland), for excellent technical assistance in laboratory activities. The authors also thank Ian Chapman and John Garrod (farm staff of the University of Sydney) and Kim McKean and Oliver Roberts (former farm managers of the University of Sydney) for their assistance in collecting samples and data. This project was supported by FutureDairy (Camden, NSW, Australia), the Dairy Research Foundation of the University of Sydney (Aus- 
tralia), and the University of Bern (Switzerland). The first author is a recipient of an Australian Endeavour PhD Scholarship.

\section{REFERENCES}

Auldist, M. J., G. O'Brien, D. Cole, K. L. Macmillan, and C. Grainger. 2007. Effects of varying lactation length on milk production capacity of cows in pasture-based dairying systems. J. Dairy Sci. 90:3234-3241. https://doi.org/10.3168/jds.2006-683.

Bansal, B. K., J. Hamann, N. T. Grabowskit, and K. B. Singh. 2005. Variation in the composition of selected milk fraction samples from healthy and mastitic quarters, and its significance for mastitis diagnosis. J. Dairy Res. 72:144-152. https://doi.org/10.1017/ S0022029905000798.

Bradley, A. 2002. Bovine mastitis: An evolving disease. Vet. J. 164:116-128. https://doi.org/10.1053/tvjl.2002.0724.

Bruckmaier, R. M., and J. W. Blum. 1998. Oxytocin release and milk removal in ruminants. J. Dairy Sci. 81:939-949. https://doi.org/10 3168/jds.S0022-0302(98)75654-1.

Bruckmaier, R. M., and M. Hilger. 2001. Milk ejection in dairy cows at different degrees of udder filling. J. Dairy Res. 68:369-376. https:/ /doi.org/10.1017/S0022029901005015.

Bruckmaier, R. M., C. E. Ontsouka, and J. W. Blum. 2004a. Fractionized milk composition in dairy cows with subclinical mastitis. Vet. Med. (Praha) 49:283-290.

Bruckmaier, R. M. D. Weiss, M. Wiedemann, S. Schmitz, and G. Wendl. 2004b. Changes of physicochemical indicators during mastitis and the effects of milk ejection on their sensitivity. J. Dairy Res. 71:316-321. https://doi.org/10.1017/S0022029904000366.

Butler, D., B. Cullis, A. Gilmour, and B. Gogel. 2009. ASReml-R Reference Manual.

Chagunda, M. G., T. Larsen, M. Bjerring, and K. L. Ingvartsen. 2006a. L-lactate dehydrogenase and N-acetyl-beta-D-glucosaminidase activities in bovine milk as indicators of non-specific mastitis. J. Dairy Res. 73:431-440. https://doi.org/10.1017/S0022029906001956.

Chagunda, M. G., N. C. Friggens, M. D. Rasmussen, and T. Larsen. 2006b. A model for detection of individual cow mastitis based on an indicator measured in milk. J. Dairy Sci. 89:2980-2998. https:/ /doi.org/10.3168/jds.S0022-0302(06)72571-1.

dos Reis, C. B., J. R. Barreiro, J. F. Moreno, M. A. Porcionato, and M. V. Santos. 2011. Evaluation of somatic cell count thresholds to detect subclinical mastitis in Gyr cows. J. Dairy Sci. 94:4406-4412. https://doi.org/10.3168/jds.2010-3776.

Dzidic, A... J. Macuhova, and R. M. Bruckmaier. 2004. Effects of cleaning duration and water temperature on oxytocin release and milk removal in an automatic milking system. J. Dairy Sci. 87:41634169. https://doi.org/10.3168/jds.S0022-0302(04)73559-6.

García, S. C., and W. J. Fulkerson. 2005. Opportunities for future Australian dairy systems: A review. Aust. J. Exp. Agric. 45:10411055. https://doi.org/10.1071/EA04143.

Gonçalves, J. L., T. Tomazi, J. R. Barreiro, D. C. Beuron, M. A Arcari, S. H. Lee, C. M. Martins, J. P. Araújo Junior, and M. V. dos Santos. 2016. Effects of bovine subclinical mastitis caused by Corynebacterium spp. on somatic cell count, milk yield and composition by comparing contralateral quarters. Vet. J. 209:87-92. https://doi.org/10.1016/j.tvjl.2015.08.009.

Gordon, W. A., H. A. Morris, and V. Packard. 1980. Methods to detect abnormal milk-A review. J. Food Prot. 43:58-64. https://doi .org/10.4315/0362-028X-43.1.58.

Halasa, T., K. Huijps, O. Østerås, H. Hogeveen, O. Osteras, H. Hogeveen, O. Østerås, and H. Hogeveen. 2007. Economic effects of bovine mastitis and mastitis management: A review. Vet. Q. 29:18-31. https://doi.org/10.1080/01652176.2007.9695224.

Haltia, L., T. Honkanen-Buzalski, A. Olkonen, and V. Myllys. 2006. A study of bovine mastitis, milking procedures and management practices on 25 Estonian dairy herds. Acta Vet. Scand. 48:22. https://doi.org/10.1186/1751-0147-48-22.
Hamann, J., and A. Zecconi. 1998. Evaluation of the electrical conductivity of milk as a mastitis indicator. Bull. IDF 334:5-26. Int. Dairy Fed., Brussels, Belgium.

Hanley, J. A., and B. J. McNeil. 1982. The meaning and use of the area under a receiver operating characteristic (ROC) curve. Radiology 143:29-36. https://doi.org/10.1148/radiology.143.1.7063747.

Hébert, A., K. Sayasith, S. Sénéchal, P. Dubreuil, and J. Lagacé. 2000. Demonstration of intracellular Staphylococcus aureus in bovine mastitis alveolar cells and macrophages isolated from naturally infected cow milk. FEMS Microbiol. Lett. https://doi.org/10.1111/j 1574-6968.2000.tb09402.x.

Hernández-Castellano, L., S. K. Wall, R. Stephan, S. Corti, and R. M. Bruckmaier. 2017. Milk somatic cell count, lactate dehydrogenase activity, and immunoglobulin G 2 concentration associated with mastitis caused by different pathogens: A field study. Schweiz. Arch. Tierheilkd. 159:283-290. https://doi.org/10.17236/sat00115.

Hillerton, J. E. 1999. Redefining mastitis based on somatic cell count. Bull. IDF 345:4-9.

Hiss, S., U. Mueller, A. Neu-Zahren, and H. Sauerwein. 2007. Haptoglobin and lactate dehydrogenase measurements in milk for the identification of subclinically diseased udder quarters. Vet. Med. (Praha) 52:245-252.

Hogan, J. S., R. N. Gonzalez, R. J. Harmon, S. C. Nickerson, S. P. Oliver, J. W. Pankey, and K. L. Smith. 1999. Laboratory Handbook on Bovine Mastitis. National Mastitis Council, Madison, WI

Højsgaard, S., and N. C. Friggens. 2010. Quantifying degree of mastitis from common trends in a panel of indicators for mastitis in dairy cows. J. Dairy Sci. 93:582-592. https://doi.org/10.3168/jds.2009 -2445 .

Hovinen, M., and S. Pyörälä. 2011. Invited review: Udder health of dairy cows in automatic milking. J. Dairy Sci. 94:547-562. https:/ /doi.org/10.3168/jds.2010-3556.

Huijps, K., T. J. Lam, and H. Hogeveen. 2008. Costs of mastitis: Facts and perception. J. Dairy Res. 75:113-120. https://doi.org/ 10.1017/S0022029907002932.

John, A. J., S. C. Garcia, K. L. Kerrisk, M. J. Freeman, M. R. Islam, and C. E. F. Clark. 2017. Short communication: The diurnal intake and behavior of dairy cows when access to a feed of consistent nutritive value is restricted. J. Dairy Sci. 100:9279-9284. https:// doi.org/10.3168/jds.2016-12245.

Kamphuis, C., R. Sherlock, J. Jago, G. Mein, and H. Hogeveen. 2008. Automatic detection of clinical mastitis is improved by in-line monitoring of somatic cell count. J. Dairy Sci. 91:4560-4570. https: //doi.org/10.3168/jds.2008-1160.

Khatun, M., C. E. F. Clark, N. A. Lyons, P. C. Thomson, K. L. Kerrisk, and S. C. García. 2017. Early detection of clinical mastitis from electrical conductivity data in an automatic milking system. Anim. Prod. Sci. 57:1226-1232. https://doi.org/10.1071/AN16707.

Khatun, M., P. C. Thomson, K. L. Kerrisk, N. A. Lyons, C. E. F. Clark, J. Molfino, and S. C. García. 2018. Development of a new clinical mastitis detection method for automatic milking systems. J. Dairy Sci. 101: 9385-9395. https://doi.org/10.3168/jds.2017 $-14310$.

Larsen, T., C. M. Røntved, K. L. Ingvartsen, L. Vels, and M. Bjerring. 2010. Enzyme activity and acute phase proteins in milk utilized as indicators of acute clinical E. coli LPS-induced mastitis. Animal 4:1672-1679. https://doi.org/10.1017/S1751731110000947.

Lehmann, M., S. K. Wall, O. Wellnitz, and R. M. Bruckmaier. 2015. Changes in milk L lactate, lactate dehydrogenase, serum albumin, and IgG during milk ejection and their association with somatic cell count. J. Dairy Res. 82:129-134. https://doi.org/10.1017/ S002202991400065X.

Lehmann, M., O. Wellnitz, and R. M. Bruckmaier. 2013. Concomitant lipopolysaccharide-induced transfer of blood-derived components including immunoglobulins into milk. J. Dairy Sci. 96:889-896. https://doi.org/10.3168/jds.2012-5410.

Milner, P., K. L. Page, and J. E. Hillerton. 1997. The effects of early antibiotic treatment following diagnosis of mastitis detected by a change in the electrical conductivity of milk. J. Dairy Sci. 80:859863 
Mollenhorst, H., L. J. Rijkaart, and H. Hogeveen. 2012. Mastitis alert preferences of farmers milking with automatic milking systems. J. Dairy Sci. 95:2523-2530. https://doi.org/10.3168/jds.2011-4993.

Mollenhorst, H., P. P. van der Tol, and H. Hogeveen. 2010. Somatic cell count assessment at the quarter or cow milking level. J. Dairy Sci. 93:3358-3364. https://doi.org/10.3168/jds.2009-2842.

Murdough, P. A., K. E. Deitz, and J. W. Pankey. 2010. Effects of freezing on the viability of nine pathogens from quarters with subclinical mastitis. J. Dairy Sci. 79:334-336. https://doi.org/10.3168/jds .s0022-0302(96)76368-3.

Nguyen, D. A., and M. Neville. 1998. Tight junction regulation in the mammary gland. J. Mammary Gland Biol. Neoplasia 3:233-246.

Nickerson, S. C. 1993. Eliminating chronic Staphylococcus aureus mastitis. Vet. Med. 88:375-381.

Norberg, E., H. Hogeveen, I. R. Korsgaard, N. C. Friggens, K. H Sloth, and P. Løvendahl. 2004. Electrical conductivity of milk: Ability to predict mastitis status. J. Dairy Sci. 87:1099-1107. https://doi.org/10.3168/jds.S0022-0302(04)73256-7.

Nyman, A. K., K. Persson Waller, T. W. Bennedsgaard, T. Larsen, and U. Emanuelson. 2014. Associations of udder-health indicators with cow factors and with intramammary infection in dairy cows. J. Dairy Sci. 97:5459-5473. https://doi.org/10.3168/jds.2013 -7885 .

Ontsouka, C. E., R. M. Bruckmaier, and J. W. Blum. 2003. Fractionized milk composition during removal of colostrum and mature milk. J. Dairy Sci. 86:2005-2011. https://doi.org/10.3168/jds .S0022-0302(03)73789-8.

Petzer, I. M., J. Karzis, E. F. Donkin, E. C. Webb, and E. M. Etter. 2017. Somatic cell count thresholds in composite and quarter milk samples as indicator of bovine intramammary infection status. Onderstepoort J. Vet. Res. 84:e1-e10. https://doi.org/10 .4102/ojvr.v84i1.1269.

Robin, X., N. Turck, A. Hainard, N. Tiberti, F. Lisacek, J. Sanchez, and M. Mueller. 2011. pROC: an open-source package for R and $\mathrm{S}+$ to analyze and compare ROC curves. BMC Bioinformatics 12:77. https://doi.org/10.1186/1471-2105-12-77.

Ruegg, P. L., D. Gleeson, A. O'Connell, K. Jordan, and B. O'Brien. 2016. The effect of storage temperature and duration on the microbial quality of bulk tank milk. J. Dairy Sci. 99:3367-3374. https:/ /doi.org/10.3168/jds.2015-10495.

Ruopp, M. D., N. J. Perkins, B. W. Whitcomb, and E. F. Schisterman. 2008. Youden index and optimal cut-point estimated from observations affected by a lower limit of detection. Biometrical J. 50:419-430. https://doi.org/10.1002/bimj.200710415.

Sargeant, J. M., K. E. Leslie, J. E. Shirley, B. J. Pulkrabek, and G. H. Lim. 2001. Sensitivity and specificity of somatic cell count and California mastitis test for identifying intramammary infection in early lactation. J. Dairy Sci. 84:2018-2024. https://doi.org/10 .3168/jds.S0022-0302(01)74645-0.

Sarikaya, H., and R. M. Bruckmaier. 2006. Importance of the sampled milk fraction for the prediction of total quarter somatic cell count. J. Dairy Sci. 89:4246-4250. https://doi.org/10.3168/jds.S0022 -0302(06)72470-5.

Shum, L. W., C. S. McConnel, A. A. Gunn, and J. K. House. 2009. Environmental mastitis in intensive high-producing dairy herds in New South Wales. Aust. Vet. J. 87:469-475. https://doi.org/10 .1111/j.1751-0813.2009.00523.x.

Sørensen, L. P., R. M. Engberg, P. Løvendahl, and T. Larsen. 2015. Short communication: Effects of Bos taurus autosome 9-located quantitative trait loci haplotypes on enzymatic mastitis indicators of milk from dairy cows experimentally inoculated with Escherichia coli. J. Dairy Sci. 98:5440-5447. https://doi.org/10.3168/ jds.2014-9071.

Swets, J. A. 1988. Measuring the accuracy of diagnostic systems. Science 240:1285-1293. https://doi.org/10.1126/science.3287615.

Tietze, K., A. Dalpke, S. Morath, R. Mutters, K. Heeg, and C. Nonnenmacher. 2006. Differences in innate immune responses upon stimulation with gram-positive and gram-negative bacteria. J. Periodontal Res. 41:447-454. https://doi.org/10.1111/j.1600-0765 .2006.00890.x

Wellnitz, O., E. T. Arnold, and R. M. Bruckmaier. 2011. Lipopolysaccharide and lipoteichoic acid induce different immune responses in the bovine mammary gland. J. Dairy Sci. 94:5405-5412. https:// doi.org/10.3168/jds.2010-3931.

Wellnitz, O., C. Zbinden, X. Huang, and R.M. Bruckmaier. 2016. Short communication: Differential loss of bovine mammary epithelial barrier integrity in response to lipopolysaccharide and lipoteichoic acid. J. Dairy Sci. 99:4851-4856. https://doi.org/10.3168/ jds.2016-10927.

Wellnitz, O., C. Zbinden, J. Lüttgenau, H. Bollwein, and R. M. Bruckmaier. 2015. Different chronological patterns of appearance of blood derived milk components during mastitis indicate different mechanisms of transfer from blood into milk. J. Dairy Res. 82:322327. https://doi.org/10.1017/S0022029915000345. 